ORIGINAL ARTICLE

\title{
Psychological Impact of the COVID-19 Pandemic on Dental Interns in Riyadh, Saudi Arabia: A Cross-sectional Survey
}

\author{
Sanjeev B Khanagar ${ }^{1}$, Abdulmohsen Alfadley ${ }^{2}$
}

\begin{abstract}
Background: Dental profession is labeled as a high-risk profession, due to which dental care professionals are under tremendous pressure during the outbreak of COVID-19 pandemic. The aim of this study was to assess the psychological impact of the COVID-19 pandemic on dental interns in Riyadh, Saudi Arabia.

Materials and methods: A cross-sectional study was conducted among dental interns from different universities in Riyadh, Saudi Arabia. The data were collected using a validated Depression, Anxiety and Stress Scale-21 Items (DASS-21) questionnaire. Descriptive statistics were presented using frequencies $(n)$ and percentages (\%). Chi-square and Fisher exact tests were used to assess the association between sociodemographic data (age, gender, nationality, marital status, and history of physical and mental illness) and levels of depression, anxiety, and stress. A $p<0.05$ was considered as statistically significant.

Results: A total of 160 dental interns were invited to participate in this survey; out of which 110 participants responded yielding a response rate of $78 \%$. The mean age of the study participants was 25.1 years. About $65 \%$ of the participants were female. Only $14.5 \%$ of the subjects reported having a past history of physical or mental illness. Depression, anxiety, and stress were identified in $11.9 \%, 7.3 \%$, and $0.9 \%$ of the dental interns, respectively. Demographic characteristics did not appear to influence depression, anxiety, or stress levels $(p>0.05)$

Conclusion: The outbreak of COVID-19 pandemic has affected the mental health of dental interns. The presence of depression, anxiety, and stress among dental interns highlights the need for special intervention and support programs to promote mental health and well-being among dental interns.
\end{abstract}

Keywords: Anxiety, COVID-19, Dental Interns, Depression, Mental Health, Psychological impact, Stress.

International Journal of Clinical Pediatric Dentistry (2020): 10.5005/jp-journals-10005-1773

\section{INTRODUCTION}

The outbreak of the coronavirus disease (COVID-19) was first reported in Wuhan city, China, in December 2019. Since then, it has rapidly spread across the world and received huge attention globally.' Later, the novel coronavirus was identified and isolated by the Chinese Center for Disease Control and Prevention (CCDC) and named it as severe acute respiratory syndrome coronavirus 2 (SARSCoV-2). The spread of infection is usually from person to person via close contact and can be transmitted through respiratory droplets of the infected person, so far this is considered the major route of transmission. ${ }^{2}$ The virus causes upper respiratory tract infections, where the infected person presents with flu-like symptoms such as fever, dry cough, running nose, fatigue, difficulty in breathing, and shortness of breath, and in severe cases, it causes symptoms similar to acute respiratory distress syndrome (ARDS) which may eventually result in respiratory arrest and death. ${ }^{2,3}$

As of May 11, 2020, the total number of confirmed COVID-19infected cases globally was 4.18M inclusive of 41,014 confirmed infected cases in Saudi Arabia. ${ }^{4}$ It is quite a known fact that healthcare workers, the first-line service providers in combating COVID-19, are exposed to hazards that put them at an elevated risk of exposure to the infectious organisms. In a recent report, a patient who underwent surgery in a hospital in Wuhan infected 14 healthcare workers even before fever onset. ${ }^{5}$ In another report, the authors reported that the School and Hospital of Stomatology, Wuhan University, that provides dental care service confirmed nine infected cases with COVID-19 among its employees. ${ }^{6}$

The Occupational Safety and Health Administration (OSHA) places dental care professionals in the category of high exposure
${ }^{1}$ Preventive Dental Science Department, Dental Public Health, College of Dentistry, King Saud Bin Abdulaziz University for Health Sciences, Riyadh, Kingdom of Saudi Arabia; King Abdullah International Medical Research Center, Ministry of National Guard Health Affairs, Riyadh, Kingdom of Saudi Arabia

${ }^{2}$ Department of Restorative and Prosthetic Dental Sciences, College of Dentistry, King Saud bin Abdulaziz University for Health Sciences, Riyadh, Kingdom of Saudi Arabia; King Abdullah International Medical Research Center, Ministry of National Guard Health Affairs, Riyadh, Kingdom of Saudi Arabia

Corresponding Author: Sanjeev B Khanagar, Preventive Dental Science Department, Dental Public Health, College of Dentistry, King Saud Bin Abdulaziz University for Health Sciences, Riyadh, Kingdom of Saudi Arabia; King Abdullah International Medical Research Center, Ministry of National Guard Health Affairs, Riyadh, Kingdom of Saudi Arabia, e-mail: sanjeev.khanagar76@gmail.com

How to cite this article: Khanagar SB, Alfadley A. Psychological Impact of the COVID-19 Pandemic on Dental Interns in Riyadh, Saudi Arabia: A Cross-sectional Survey. Int J Clin Pediatr Dent 2020;13(5):508-512.

Source of support: Nil

Conflict of interest: None

risk, as the dental profession jobs are at higher risk for exposure to the infectious viruses known to cause COVID-19 while performing dental procedures. ${ }^{7}$

This could be based on the fact that the spread of infectious microorganisms in a dental setting could be through the bioaerosols that are generated during the dental procedures. The spread of infectious microorganisms could also be through other 
routes like contact from salivary and nasopharyngeal droplets from infected patients, direct contact with contaminated instruments or dental water supply system, and cross-contaminations from inanimate surfaces within the dental settings. ${ }^{8,9}$

The ongoing disastrous impact of this pandemic has posed significant challenges for clinical dentistry. For instance, the fact that dentistry is associated with the elevated exposure risk for the disease places oral healthcare providers under high psychological pressure during patient care.

Even though most of dental care settings have been suspended in countries experiencing COVID-19 pandemic, dental care professionals are still reported of undergoing enormous physical and psychological pressure, knowing the fact of being at a higher risk group. ${ }^{10,11}$ A recent study has addressed the stress among medical students at a health university in Saudi Arabia during the outbreak of Middle East respiratory syndrome-related coronavirus (MERS-CoV). ${ }^{12}$ Hence, the aim of this study was to assess the psychological impact of the COVID-19 pandemic on dental interns in Riyadh, Saudi Arabia. More specifically, this study sought to assess depression, anxiety, and stress among dental interns and determine the effect of certain demographic and health variables on participants' responses.

\section{Materials and Methods}

A cross-sectional study was conducted among dental interns to assess the psychological impact of the COVID-19 pandemic. The ethical clearance was obtained from the Institutional Review Board (IRB) before the initiation of the study (RC20/263/R, IRB NCBE Reg. No H-01-R-005). Required sample size was estimated based on the results of a recently published study. ${ }^{13}$ Using $10 \%$ relative precision and $95 \%$ confidence level, the required sample size was 157 , which was rounded off to $160 .{ }^{14}$ The data were collected from the dental colleges located in Riyadh, Saudi Arabia.

Dental interns who were willing to participate were included in this study, and written informed consent was obtained from those participants. The data were collected using a web-based questionnaire that was sent to study participants. The questionnaire was designed after referring to similar studies reported in the literature. The questionnaire consisted of two sections, the first section consisted of demographic data which included the age, gender, nationality, marital status, and history of physical and mental illness followed by the second section which included the prevalidated Depression, Anxiety and Stress Scale-21 Items (DASS-21). ${ }^{15}$ DASS-21 consists of seven items each, related to depression, anxiety, and stress. An individual's perception is assessed on a four-point scale of did not apply to me at all, applied to me to some degree, applied to me to a considerable degree, and applied to me very much. Scores were calculated by adding the scores for the relevant items and interpreted as normal, mild, moderate, severe, and extremely severe.

The feasibility of the questionnaire was assessed by conducting a pilot study among the interns in our college. The data were entered and analyzed using SPSS version 23 (IBM Corporation, Armonk, NY, USA). Since all the variables described in the attached questionnaire are categorical variables, the data were summarized as proportions. The Chi-square and Fisher exact tests were used to assess the association between sociodemographic data (age, gender, nationality, marital status, and history of physical and mental illness) and levels of depression, anxiety, and stress. A $p<0.05$ was considered as statistically significant.

\section{Results}

Out of the 160 interns who were contacted to participate in this study, 110 filled the questionnaire yielding an overall response rate of $78 \%$. Table 1 shows the descriptive statistics based on demographic variables of study participants. The mean age of the participants was 25.1 years. About $65 \%$ of the participants were female. Only $14.5 \%$ of the subjects reported having a past history of physical or mental illness. The summary of the responses towards the questions related to DASS-21 is presented in Table 2. In general, most of the respondents expressed low DASS-21 scores.

Table 3 describes the comparisons between depression, stress, and anxiety levels in relation to age, gender, nationality, marital status, and medical history of participants. Interestingly, there were no statistically significant differences with any of these variables. In the present study, the prevalence of depression, anxiety, and stress was found to be $11.9 \%, 7.3 \%$, and $0.9 \%$, respectively (see Table 4).

\section{Discussion}

The aim of this study was to assess the psychological impact of the COVID-19 pandemic on dental interns in Riyadh, Saudi Arabia. The participants reported experiencing varying levels of mental health symptoms during the outbreak of COVID-19.

A recent study assessing the mental health status of dental care providers during the outbreak of COVID-19 has reported that dentists are under increased pressure and have reported high levels of fear and psychological distress during this outbreak. ${ }^{11}$ Another study also investigated the mental health status of dentists during the COVID-19 outbreak and found different levels of fear and anxiety among dentists from 30 countries. ${ }^{10}$ These studies have reported high proportion of participants experiencing depression, anxiety, and stress. This could be attributed to the fact that the ongoing pandemic is transmissible between humans and is also potentially fatal. This might be a reason for this self-reported behavior. Dental care providers are at a high risk of being exposed to the infectious disease, which might intensify the perception of personal danger. The fear of being exposed at work during their clinical hours has affected the mental health of dental interns.

Table 1: Descriptive statistics of demographic variables

\begin{tabular}{llcc}
\hline Variable & & Frequency & Percentage \\
\hline Age & 22 & 1 & 0.9 \\
& 23 & 22 & 20 \\
& 24 & 40 & 36.4 \\
& 25 & 36 & 32.7 \\
Sex & 26 & 10 & 9.1 \\
\multirow{4}{*}{ Nationality } & 31 & 1 & 0.9 \\
& Male & 39 & 35.5 \\
Marital status & Female & 71 & 64.5 \\
& Saudi & 109 & 99.1 \\
Medical history & Mon-Saudi & 1 & 0.9 \\
& Ynmarried & 9 & 8.2 \\
& Yes & 100 & 90.9 \\
& No & 94 & 14.5 \\
\hline
\end{tabular}


Table 2: Percentage of DASS-21 responses

\begin{tabular}{|c|c|c|c|c|c|}
\hline & & $\begin{array}{l}\text { Did not apply } \\
\text { to me at all }\end{array}$ & $\begin{array}{l}\text { Applied to me } \\
\text { to some degree }\end{array}$ & $\begin{array}{l}\text { Applied to me to a } \\
\text { considerable degree }\end{array}$ & $\begin{array}{l}\text { Applied to me } \\
\text { very much }\end{array}$ \\
\hline \multirow[t]{7}{*}{ Depression } & $\begin{array}{l}\text { I couldn't seem to experience any positive feeling } \\
\text { at all }\end{array}$ & 55 & 34 & 14 & 7 \\
\hline & $\begin{array}{l}\text { I found it difficult to work up the initiative } \\
\text { to do things }\end{array}$ & 50 & 30.9 & 12.7 & 6.4 \\
\hline & I felt that I had nothing to look forward to & 44.5 & 35.5 & 13.6 & 6.4 \\
\hline & I felt down-hearted and blue & 56.4 & 32.7 & 9.1 & 0.9 \\
\hline & $\begin{array}{l}\text { I was unable to become enthusiastic about } \\
\text { anything }\end{array}$ & 54.5 & 32.7 & 9.1 & 3.6 \\
\hline & I felt I wasn't worth much as a person & 74.5 & 15.5 & 7.3 & 2.7 \\
\hline & I felt that life was meaningless & 59.1 & 30.9 & 6.4 & 3.6 \\
\hline \multirow[t]{7}{*}{ Anxiety } & I was aware of dryness of my mouth & 71.8 & 19.1 & 6.4 & 2.7 \\
\hline & $\begin{array}{l}\text { I experienced breathing difficulty (e.g. } \\
\text { excessively rapid breathing, breathlessness } \\
\text { in the absence of physical exertion) }\end{array}$ & 85.5 & 10.9 & 3.6 & 0 \\
\hline & I experienced trembling (e.g. in the hands) & 84.5 & 13.6 & 0.9 & 0.9 \\
\hline & $\begin{array}{l}\text { I was worried about situations in which I might } \\
\text { panic and make a fool of myself }\end{array}$ & 60.9 & 30 & 7.3 & 1.8 \\
\hline & I felt I was close to panic & 69.1 & 23.6 & 6.4 & 0.9 \\
\hline & $\begin{array}{l}\text { I was aware of the action of my heart in the } \\
\text { absence of physical exertion (e.g. sense of } \\
\text { heart rate increase, heart missing a beat) }\end{array}$ & 73.6 & 16.4 & 4.5 & 5.5 \\
\hline & I felt scared without any good reason & 63.6 & 25.5 & 9.1 & 1.8 \\
\hline \multirow[t]{7}{*}{ Stress } & I found it hard to wind down (relax) & 31.8 & 49.1 & 15.5 & 3.6 \\
\hline & I tended to over-react to situations & 50.9 & 32.7 & 11.8 & 4.5 \\
\hline & I felt that I was using a lot of nervous energy & 58.2 & 26.4 & 12.7 & 2.7 \\
\hline & I found myself getting agitated (upset) & 47.3 & 30.9 & 15.5 & 6.4 \\
\hline & I found it difficult to relax & 41.8 & 46.4 & 10.9 & 0.9 \\
\hline & $\begin{array}{l}\text { I was intolerant of anything that kept me from } \\
\text { getting on with what I was doing }\end{array}$ & 57.3 & 26.4 & 13.6 & 2.7 \\
\hline & I felt that I was rather touchy (oversensitive) & 41.8 & 39.1 & 10 & 9.1 \\
\hline
\end{tabular}

Table 3: Association of depression, anxiety, and stress scores among sociodemographic characteristics

\begin{tabular}{|c|c|c|c|c|c|c|c|c|c|}
\hline & \multicolumn{3}{|c|}{ Depression, $\varnothing(N=110)$} & \multicolumn{3}{|c|}{ Anxiety, $\varnothing(N=110)$} & \multicolumn{3}{|c|}{ Stress, $\varnothing(N=110)$} \\
\hline & $\chi^{2}$ & $d f$ & $p$ value & $\chi^{2}$ & $d f$ & $p$ value & $\chi^{2}$ & $d f$ & $p$ value \\
\hline Age & 6.32 & 12 & 0.899 & 5.07 & 12 & 0.956 & 11.32 & 6 & 0.079 \\
\hline Gender & 1.62 & 2 & 0.445 & 1.14 & 2 & 0.565 & 0.554 & 1 & 0.457 \\
\hline Nationality & 0.124 & 2 & 0.94 & 0.079 & 2 & 0.961 & 0.009 & 1 & 0.923 \\
\hline Marital status & 1.54 & 2 & 0.463 & 0.755 & 2 & 0.685 & 11.21 & 1 & 0.083 \\
\hline Medical history & 1.357 & 2 & 0.507 & 2.099 & 2 & 0.35 & 0.172 & 1 & 0.679 \\
\hline
\end{tabular}

Ø: Chi-square analysis

Table 4: Levels of depression, anxiety, and stress among study participants

\begin{tabular}{lccc}
\hline Levels & $\begin{array}{l}\text { Depression, } N \\
(\%)\end{array}$ & Anxiety, N (\%) & Stress, N (\%) \\
\hline Normal & $98(89.1)$ & $102(92.7)$ & $109(99.1)$ \\
Mild & $7(6.4)$ & $2(1.8)$ & $1(0.9)$ \\
Moderate & $5(4.5)$ & $6(5.5)$ & $0(0)$ \\
Total & $110(100)$ & $110(100)$ & $110(100)$ \\
\hline
\end{tabular}

In the present study, the psychological impact of the COVID 19 pandemic on dental interns was assessed using the validated the DASS, which is a standardized self-report scale which measures all the three domains of emotional states of an individual, which mainly includes depression, anxiety, and stress at a time. The DASS is mainly developed to maximize discrimination between the three components it measures. The DASS has shown high reliability and validity at measuring anxiety and depression in both clinical and community samples. ${ }^{15,16}$ The DASS-21 which was used in this study 
is a short version of the DASS-42 and has the advantage of being less time-consuming and more consistent when compared to the full-scale version. ${ }^{15,16}$

Majority of the studies which have reported on the mental health status of dental students have used DASS for assessing the mental health variables. Studies reported on the mental health status of dental students have revealed that dental students undergo a lot of mental health stress and depression. To our surprise in the present study, the prevalence of depression, anxiety, and stress was $11.9 \%, 7.3 \%$, and $0.9 \%$, respectively. These scores were comparatively less, when compared to the results of studies reported in the literature. Our results showed that dental interns experienced less psychological symptoms compared to the results of a study conducted on dental students in Saudi Arabia, which revealed that $55.9 \%, 66.8 \%$, and $54.7 \%$ of the study participants experienced depression, anxiety, and stress, respectively, ${ }^{13}$ and also with the results of a study conducted in Mecca region of Saudi Arabia that reported the elevated levels of DASS scores among students. ${ }^{17}$ Another study conducted in Kuantan, Malaysia, also reported a higher prevalence of depression, anxiety, and stress among study participants. ${ }^{18}$ Another study conducted among dental students in Selangor, Malaysia, also reported high levels of depression, anxiety, and stress scores among study participants. ${ }^{19}$ Similar results were reported from studies conducted on dental students in Denmark, ${ }^{20}$ India, ${ }^{21}$ Pakistan, ${ }^{5}$ and Jordan. ${ }^{23}$ The elevated levels of depression, anxiety, and stress levels in cited studies were attributed to the pressure that is exerted on dental students during the dental education by their workload, clinical requirements, examinations, and with the competition that persists throughout years of study. ${ }^{24,25}$ In our study, however, dental interns expressed lower levels of DAS scores when compared to the reports mentioned above. This could be attributed to the timing of data collection. In the present study, the data were collected during the lockdown period that coincided with the end of the academic year, where participants were completely relieved from their clinical duties. This could be a reason for reporting bias, which could have affected the results of our study.

In the present study, we also assessed the association between age, gender, nationality, marital status, and medical history of the study participants with that of depression, anxiety, and stress levels, but there were no statistically significant results found. The previously reported studies have shown that female students reported higher levels of stress and anxiety when compared to male participants. ${ }^{17,19,22,25-27}$ Few studies conducted on dental students have also reported that male students were more affected than female students. ${ }^{24,28}$ In the previously published studies, married students showed more symptoms than the unmarried ones. ${ }^{21}$ In the present study, very few participants were married, and marital status did not seem to affect the psychological status of participants. Of note is that around $15 \%$ of the participants reported that they had a past history of physical or mental illness, but this did not have any impact on their responses.

This study has its own limitations. For instance, data collection was accomplished using a questionnaire-based online survey. Therefore, the probability of reporting bias should be considered. Furthermore, data collection was performed during the lockdown period and after the completion of the academic year. Since the interns were completely relieved from their clinical duties, there could be a chance of underreporting. In addition to that, this study did not take into consideration the difference in depression, anxiety, and stress levels at variable times, which is before and after the outbreak of COVID-19.

\section{Conclusion}

The present study found that a few percentage of the study population were affected by the outbreak of COVID-19 and have revealed symptoms of mental health issues. This could be because of the contagious nature of this respiratory disease. Being aware of the fact that dentists are at a higher risk could have had an impact on the mental health status of participants. Dental interns facing mental health issues should be provided with professional counseling. Moreover, special intervention programs should be developed to promote mental health and well-being among these young dental professionals.

\section{References}

1. Zhu N, Zhang D, Wang W, et al. A novel coronavirus from patients with pneumonia in china, 2019. N Engl J Med 2020(8). DOI: 10.1056/ NEJMoa2001017.

2. Huang C, Wang Y, Li X, et al. Clinical features of patients infected with 2019 novel coronavirus in Wuhan, China. Lancet 2020;395(10223): 497-506. DOI: 10.1016/S0140-6736(20)30183-5.

3. Wang D, Hu B, Hu C, et al. Clinical characteristics of 138 hospitalized patients with 2019 novel coronavirus-infected pneumonia in Wuhan, China. JAMA 2020;323(11):1061-1069. DOI: 10.1001/jama.2020. 1585.

4. World Health Organization Coronavirus disease (COVID-2019) situation report - 112 https://www.who.int/emergencies/diseases/ novel-coronavirus-2019/situation-reports.

5. Chang $D, X u H$, Rebaza A, et al. Protecting health-care workers from subclinical coronavirus infection the lancet respiratory medicine. Lancet Respir Med 2020;8(3):e13. DOI: 10.1016/ S2213-2600(20) 30066-7.

6. Meng L, Hua F, Bian Z. Coronavirus disease 2019 (COVID-19): emerging and future challenges for dental and oral medicine. J Dent Res 2020(1):1-7. DOI: https://journals.sagepub.com/doi/full/10.1177/002 2034520914246 Accessed on April 1, 2020.

7. Guidance on Preparing Workplaces for COVID-19. https://www.osha. gov/Publications/OSHA3990.pdf Accessed on 11 May 2020.

8. Peng X, Xu X, Li Y, et al. Transmission routes of 2019-nCoV and controls in dental practice. Int J Oral Sci 2020;12(1):9. DOI: 10.1038/s41368-0200075-9.

9. Geiger UA,. Dental infection control. [Updated 2020 Feb 17]. In: StatPearls [Internet]. . Treasure Island (FL): StatPearls Publishing; 2020. Available from https://www.ncbi.nIm.nih.gov/books/NBK470356/ Accessed March 16, 2020.

10. Ahmed MA, Jouhar R, Ahmed N, et al. Fear and practice modifications among dentists to combat novel coronavirus disease (COVID-19) outbreak. Int J Environ Res Public Health 2020;17(8):2821. DOI: 10.3390/ijerph17082821.

11. Shacham M, Hamama-Raz Y, Kolerman R, et al. COVID-19 factors and psychological factors associated with elevated psychological distress among dentists and dental hygienists in Israel. Int J Environ Res Public Health 2020;17(8):2900. DOI: 10.3390/ijerph17082900.

12. Al-Rabiaah A, Temsah MH, Al-Eyadhy AA, et al. Middle east respiratory syndrome-corona virus (MERS-CoV) associated stress among medical students at a university teaching hospital in Saudi Arabia. J Infect Public Health 2020;13(5):687-691. DOI: 10.1016/j.jiph.2020. 01.005 .

13. Basudan S, Binanzan N, Alhassan A. Depression, anxiety and stress in dental students. Int J Med Educ 2017;8:179-186. DOI: 10.5116/ ijme.5910.b961. 
14. Lemeshow S, Hosmer DW, Klar J, et al. Adequacy of Sample Size in Health Studies. John Wiley and Sons; 1990.

15. Lovibond SH, Lovibond PF. Manual for the Depression Anxiety \& Stress Scales. 2nd ed., Sydney: Psychology Foundation; 1995.

16. Westerman GH, Grandy TG, Ocanto RA, et al. Perceived sources of stress in the dental school environment. J Dent Educ 1993;57(3):225231. DOI: 10.1002/j.0022-0337.1993.57.3.tb02732.x.

17. Aboalshamat $K$, Hou X-Y, Strodl E. Psychological wellbeing status among medical and dental students in Makkah, Saudi Arabia: a cross-sectional study. Med Teach. 2015;37(S1):S75-S81. DOI: 10.3109/0142159X.2015.1006612.

18. Yaacob M, Harun NA, Ramli F, et al. Depression, anxiety and stress among dental undergraduate students: prevalence, stressors and relieving factors. IMJM 17(Special Issue No 2):123-130.

19. Radeef AS, Faisal GG. Stressors and their association with symptoms of depression, anxiety and stress in dental students. Makara J Health Res 2018;22(2):58-62. DOI: 10.7454/msk.v22i2.9064.

20. Moore R, Madsen LV, Trans M. Stress sensitivity and signs of anxiety or depression among first year clinical dental and medical students. Open J Med Psychol 2020;9(2):7. DOI: 10.4236/ojmp.2020.91002. https://www.scirp.org/journal/ojmp.

21. Sravani A, Doshi D, Kulkarni S, et al. Depression, anxiety, and stress among undergraduate dental students in Hyderabad city, Telangana,
India: a cross-sectional study. J Indian Assoc Public Health Dent 2018;16(1):26-29. DOI: 10.4103/jiaphd.jiaphd_10_17.

22. Naz N, lqbal S, Mahmood A. Stress, anxiety and depression among the dental students of university college of medicine and dentistry Lahore; Pakistan. PJMHS 2017;11(4).

23. Abu-Ghazaleh SB, Rajab LD, Sonbol HN. Psychological stress among dental students at the university of Jordan. J Dent Educ 2011;75(8):1107-1114. DOI: 10.1002/j.0022-0337.2011.75.8.tb05156.x.

24. Alzahem AM, Van der Molen HT, Alaujan AH, et al. Stress amongst dental students: a systematic review. Eur J Dent Educ 2011;15(1):8-18. DOI: 10.1111/j.1600-0579.2010.00640.x.

25. Al-Sowygh ZH, Alfadley AA, Al-Saif Ml, et al. Perceived causes of stress among saudi dental students. King Saud Univer J Dent Sci 2013;4(1):7-15.

26. Takayama Y, Miura E, Miura K, et al. Condition of depressive symptoms among Japanese dental students. Odontology 2011;99(2):179-187. DOI: 10.1007/s10266-011-0005-6.

27. Telang HA, Nerali JT, Telang A, et al. Perceived sources of stress among Malaysian dental students. European J Gen Dent 2013;2(30):300-307. DOI: 10.4103/2278-9626.116020.

28. Peker I, Alkurt MT, Usta MG, et al. The evaluation of perceived sources of stress and stress levels among Turkish dental students. Int Dent J 2009;59(2):103-111. 